\title{
A Process Model of Partnership Evolution Around New IT Initiatives
}

\author{
Timo Kestilä ${ }^{1}$, Lauri Salmivalli ${ }^{2}$, Hannu Salmela ${ }^{1}$, Annukka Vahtera ${ }^{1}$ \\ 1 Turku School of Economics, Information Systems Science \\ 2 Turku School of Economics, Pori Unit, Welfare Economics
}

\begin{abstract}
Prior research on inter-organizational information systems has focused primarily on dyadic network relationships, where agreements about information exchange are made between two organizations. The focus of this research is on the processes through which IT decisions are made within larger inter-organizational networks with several network parties. The research draws from network theories in organization science to identify three alternative mechanisms for making network level commitments: contracts, rules and values. In addition, theoretical concepts are searched from dynamic network models, which identify different cycles and stages in network evolution. The empirical research was conducted in two networks. The first one comprises of four municipalities which began collaboration in the deployment of IT in early childhood education (ECE). The second network involves a case where several organizations, both private and public, initiated a joint effort to implement a national level electronic prescription system (EPS). The frameworks and concepts drawn from organizational theories are used to explain success of the first case and the failure of the latter case. The paper contributes to prior IOS research by providing a new theory-based framework for the analysis of early stages of building organizational networks around innovative IT initiatives.
\end{abstract}

\section{Introduction}

Despite the critical role of computers in inter-organizational arrangements, coordination of IT decisions within these networks is a fairly unexplored area, both in research and in practice. The processes through which the orchestration of IT in networks takes place are largely hidden. However, many initiatives to coordinate IT decisions fail within networks. These failures are not necessarily very visible and thus get very little attention. 
This research investigates the processes through which networks can reach agreements on the use of IT. The research problem is formulated as follows: How to build and maintain inter-organizational cooperative network for IT collaboration? The practical objective is to provide methods for managers starting up interorganizational network to foster a specific IT related collaborative idea. It is suggested, however, that the networks differ in terms of dominant coordination mechanisms. Hence, the group should employ methods that fit with the general coordination style of the network.

We acknowledge the dynamic nature of networks: the explanations for outcomes are process theories, rather than variance theories [1]. Preconditions and situational variables are not, as such, sufficient to explain outcomes. The outcomes result from the interplay between initial conditions, contextual changes, and process events and Ring and Van de Ven (1994) argue that there are less empirical knowledge about how Inter-Organizational Relationships (IORs) emerge, grow, and dissolve over time than there are about success factors and failures of IORs [2]. Therefore, it is relevant to ask, how the inter-organizational relationships are being developed. Field work in this article has done in two networks. One was a relative failure and the second one was success. Both ICT networks were in early stages and research was conducted with action research approach.

\section{A process model of partnership evolution}

Within Information Systems Science, the research draws from the research tradition around Inter-Organizational Systems (IOS). Research on strategic IS management, and more recently that of IT governance, will also be used as a theoretical background. While most of the studies in this area address IS management and governance mainly as taking place within a single firm, some researchers have already identified the need to incorporate network level considerations. For instance, Finnegan et al. argue that there is growing need for inter-organizational IS planning [3]. This argument is further developed by Salmela and Spil [4].

Perhaps the most fundamental difference between a network and an organization is the lack of a single authority to ensure coordination of actions. Absence of a single authority has led networks to employ a wide array of mechanisms to be used for building and maintaining commitment to joint efforts. These mechanisms have intrigued researchers in many fields, such as economics [5], strategic management [6], organization science [7], marketing [8], sociology [9], information systems [10] [11] and strategic information systems planning [12].

An inter-organizational relationship (IOR) can be defined as "a social action system on the premise that it exhibits the basic elements of any organized form of collective behavior" [13]. These IORs include strategic alliances, partnerships, coalitions, joint ventures, franchises, research consortia and various forms of network organizations [2].

The effects of the contingencies on inter-organizational cooperation vary between different types of IORs. Four basic types can be identified ([14]): Hierarchical, Solar, Centreless and Swingle. According to Wilson (1995) a process model for the 
development of inter-organizational relationship includes the following steps: partner selection, purpose definition, relationship boundaries setting, relationship value creation and relationship maintenance[15]. Ring and Van de Ven (1994) claim that the development and evolution of a cooperative inter-organizational relationship consists of a repetitive sequence of negotiation, commitment and execution phases [2].

The framework is presented in Figurelwhere each phase is assessed in terms of efficiency and equity. Even though the temporal occurrence of these phases may be almost simultaneous in simple transactions, the duration of each stage varies according to the uncertainty of issues involved, the reliance on trust among the parties to a cooperative IOR and the role relationships of the parties.

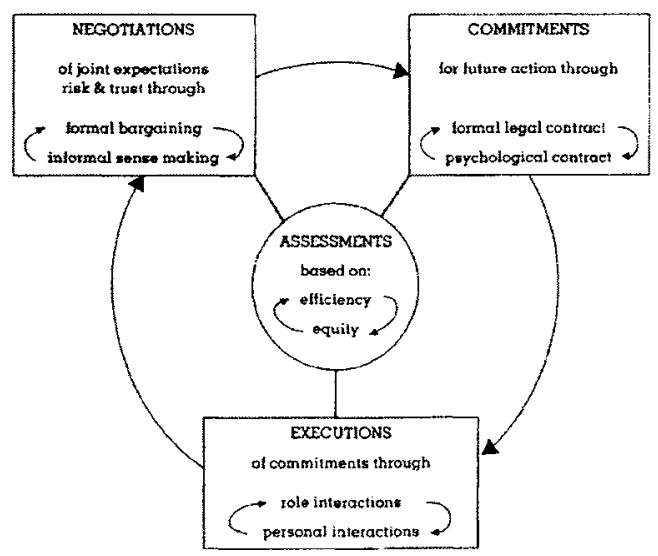

Figure 1: Process Framework of the development of cooperative Inter-organizational relationships [2]

Below, a more detailed description of different stages is given:

- Negotiations stage: In this stage the parties develop joint expectations about their motivations, possible investments and perceived uncertainties of a business deal they are exploring to undertake jointly. The focus in this stage is on the formal bargaining processes. These processes are often necessary in order to provide participants opportunities to assess uncertainty associated with the deal, the nature of each other's role, the other's trustworthiness, their rights and duties, and possible efficiency and equity of the transaction as it relates to all parties.

- Commitments stage: Participants reach an agreement on the obligations and rules for future action in the relationship. The terms and governance structure of the relationship are established in this stage. These agreements are either aggregated in a formal legal contract or informally understood psychological contract.

- Executions stage: In this stage, the commitments and rules of action are carried out. Initially, parties' formally designated role behavior reduces the uncertainty and makes interactions among parties also more predictable. After a while, parties may 
become more familiar with each other and they may increasingly begin to rely on interpersonal relationships.

In many cases, a cooperative IOR may need to remain in effect for a long time. Misunderstandings, conflicts and changing expectations are inevitable and they might cause renegotiations. In the final cycle of the process, the parties may conclude that the relationship should be terminated. This typically occurs when the parties have lived up their promises and the deal is completed. Ring and Van de Ven (1994) assume that participative organization have motivations to the network [2]. In this paper we assume that in pre-stage and early stage the motivation exist but it is unconscious and weak and is therefore needed to be strengthened.

Transaction economy has traditionally seen two possible ways for managing exchange: hierarchy and market. Market exchanges are transactions between separate entities whereas hierarchical relationships are coordinated through unitary organizational structures [16]. Ouchi has expanded Williamson's model by adding clan as one form of exchange and has renamed hierarchy to bureaucracy. [17]

According to Rodriguez et al. (2007) all three kind of governance mechanism play different but essential role in stimulating effective inter-organizational collaboration [18]. In Figure2 we describe these mechanisms and key motivations behind it. The mechanisms are present constantly and have to be considered in every phase of IOR process.

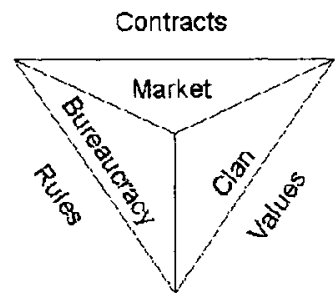

Figure 2: Coordination mechanism and key motivators [17]

In this paper we combine Ring and Van de Ven (1994) process framework in Figure and Ouchi's coordination mechanisms in Figure [2, 17]. Market, bureaucracy and clan mechanism are constantly present in properly operating interorganizational union. Market and bureaucracy are needed for manage participants opportunism and clan for creating value and fairness [19]. In Figure 3 is presented the framework for analyzing IOR in different stages. This framework will be used to analyze our two cases. 


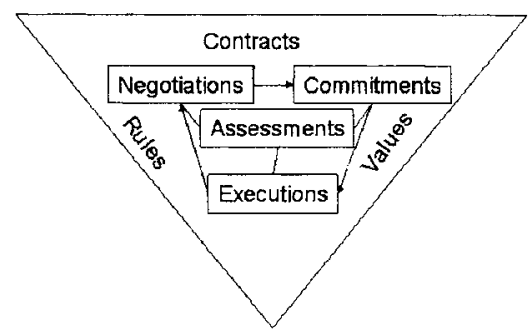

Figure 3 Framework for creating IOR

\section{Cases}

In this chapter we introduce two eGovernment projects in Finland where the authors have been participating as action researchers.

Rapoport [20, 499] has defined action research as: "Action research aims to contribute both to the practical concerns of people in an immediate problematic situation and to the goals of social science by joint collaboration within a mutually acceptable ethical framework." This twofold view of the objectives of action research - to solve a problem for a client and to advance science - is, perhaps, the most fundamental feature of action research $[21,22]$. Because action research is a qualitative research method with a small sample size, it is vulnerable to positivist critics [23]. Because it attempts to contribute to practical concerns, it is sometimes confused with applied research or consulting [24]. However, action research can follow rigorous guidelines. One of the principal guidelines for conducting action research is that researchers should make their reasoning explicit and organize it in such a way that it is testable [25]

Data was collected from documents, interviews and participatory observation (including researcher diary and group discussions). The first case can be considered as successful IOR venture and the second one as relatively failed IOR.

The first case describes four municipality's common ICT governance project. Participants were daycare professional and their management. The second reports findings from fifteen semi-structured interviews made to main actors in the Finnish Electronic Prescription System (EPS) pilot. Interviewees were on the management level in their organizations.

\section{Case 1: ICT in the Finnish Early Childhood Education}

This case demonstrates the creation of ICT utilization oriented network in the context of early childhood education (ECE). In Finland, every child has a statutory subjective right to receive public day-care and the municipalities are responsible to organize a placement according to demand.

The creation of ICT utilization oriented network began in 2004. In the first phase in 2004-2005 the initiative business idea was developed and the possible actors to the 
network were outlined. In the fall of 2005 the foundation of the network was established. In the early 2006 the participative organizations made an agreement about a common development project and filled in a funding application for one year long developing project to the Finnish Ministry of Social Affairs and Health. The positive decision was received in May 2006 which led to an establishment of a steering group with representatives from four municipalities and two universities in South-West Finland.

The initial developing work started in fall 2006 with orientation lecture. A total of 50 ECE professionals with different professional backgrounds varying from the Director of ECE to daycare teachers and administrative officers participated in the developing process. Altogether over 150 people were involved in the network to a certain degree during the years 2004-2007. The negotiations and planning for the follow-up development project began in the beginning of 2007. Three municipalities decided to continue cooperation, and new funding application for two year's followup development project was filled. In spring 2007 the follow-up project was admitted a funding decision.

\section{Case 2: Implementation of Electronic Prescription System}

The second case reports findings from the Finnish Electronic Prescription System (EPS) pilot. In 2000 the Ministry of Social Affairs and Health set a project to suggest a national concept for ePrescribing. The construction of the system took 2 years, and the first clinical pilot started in 2004. By the end of 2004 two out of the four piloting health care units had implemented the EPS integrated into Electronic Patient Record (EPR), pilot pharmacies still used a stand-alone system, which was not integrated into pharmacy systems and created extra work at the pharmacies. In June 2005, the third integrated EPS and the first integrated pharmacy system were implemented. The amount of produced e-prescriptions remained very small during the pilot and at the end of 2005 only approximately 800 electronic prescriptions had been dispensed (there are approximately 40 million dispensed prescriptions in Finland annually). In June 2006 the EPS pilot was ended, because it had "reached the objectives set to it".

\section{Discussion}

We divided the both cases in three different stages based on our framework.

\section{Negotiations stage}

In the $E C E$ case the participation of one particular ECE researcher in was important to the project's success. She had worked as researcher in many ECE development projects and was therefore familiar for most of the ECE managers. The presence of the ECE researcher invoked confidence among the ECE participants and further interpreted IS researchers' ICT based concepts and terms to the ECE professionals.

During the development process one seminar for ECE software vendors was organized. The firms were not interested in participating networks. Behind the refusals were many reasons: cooperation with competitor is always difficult and the 
advantage from participation was difficult to see. We argue that the main reason in the terms of our coordination mechanism framework was incompatible values between competitors and especially between the ECE people.

In the EPS case the preliminary work was thoroughly prepared. The Ministry of Social Affairs and Health set already in 2000 a preliminary disquisition project in order to suggest a national model for electronic prescription in order to harmonize the development. The work was done in line with the Finnish National eHealth Strategy, in collaboration with experts in different fields. In 2001 published expert report described alternative architectures for a national EPS, their strengths and weaknesses. The Ministry selected in 2002 four health care organizations and Pharmacy Association and University Pharmacy selected a couple of nearby pharmacies in four different regions for clinical tests of the pilot system. Yet it can be argued whether the negotiations stage really achieved to develop joint expectations about the motivations of the project. The interviewees claimed that the objectives of the pilot were expressed vaguely in the first place.

\section{Commitments stage}

In the first, $\boldsymbol{E} \boldsymbol{C E}$ case, the researchers presented preliminary proposal to the managers and asked what their personal level commitment to participation were and what was their organizations' interest. The discussions with the managers increased organizations' interested in participating to the network. The development project needed funding. In Finland state supports municipalities in their development projects. The funding application form has to include things like project plan, governance model, budget etc. The application form serves as a legal agreement between the participating municipalities, too. According to our framework was the application market-based agreement, which created some administrative and bureaucratic structure and had symbolic value, too. In the application phase the role of the contract is essential. The contract created some rules, too. The interorganizational contract in turns enforced commitment of the members from participating organizations [2]. After the positive funding decision was received, the actual inter-organizational cooperation started fast. A steering group with chairman was established, and development work plan was specified. The agreements about fiscal matters between participating organizations were signed. The members of the steering group had worked with the initial application together and had therefore created a common value space for this project.

In Finland health care is strictly regulated by legislation. The EPS pilot suffered from incompleteness of legislation which in turn hindered the pilot. An experimental decree on electronic prescribing was issued in 2003. It laid down provisions on preparing, signing, technical content, altering and delivery of electronic prescriptions. There were also provisions on informing patients and obtaining their consent, defining the rights of access to database and maintaining information in the national database. Yet the situation would have been eased if actors had have contracts among each other defining the rights and responsibilities in the pilot.

The interviewees claimed that they were committed to EPS implementation project, and generally respondents didn't see that there were any major conflicts of interest. Yet, some respondents argued that a certain trusteeship organization was having its own agenda, and is hindering the work of steering group. Participating organizations did not receive any financial incentives for participation, but instead they were 
expected to allocate resources for the pilot. Hence, members participated the project among their other tasks.

\section{Executions stage}

In the end of 2007 the negotiations for a new $E C E$ development project began. Members in the steering group and workgroups were asked how and which of the development proposals should be implemented. According to the answers, the foundation for further development project was formulated. Three municipalities showed their interest to continue IOR cooperation. Funding application was delivered to Ministry of Health and Social Affair. After positive decision a two year long development project started.

The EPS pilot was a peculiar combination of different governance methods. The construction of the system took 2 years, and the first clinical pilot started in 2004. By the end of 2005 two out of the four piloting health care units had implemented EPS integrated into an electronic patient record (EPR), and in one area an integrated pharmacy system was implemented to dispense electronic prescriptions. The amount of electronic prescriptions remained very small until the end of the pilot. As one of the biggest reasons for this was that the pilot was foremost seen as a technical pilot. This was reflected among other things as low usage in the actual use.

The actual management was conducted through national steering group which had little normative rules to affect the pilot, some of the interviewees referred to it as a debating club. The steering group coordinated the locally organized pilots with a small budget. Additionally, the pilot was coordinated at first hand by a part-time project manager designated by the Ministry of Health. The project manager had little means to influence the network, as the contractual jurisprudence was lacking, the project lost its final coordination mechanism. Furthermore, in the spring 2005 the organization of the national e-prescription pilot was changed thoroughly; the part time project manager of the pilot was changed to a major consultancy company, which re-organized the administration of pilot entirely.

There was a broad conception among interviewees that the execution of the pilot was a failure. Time scale of the project was drawn out constantly, the pilot was under-resourced both in terms of money and personnel, and responsibilities were not clear. Several interviewees reported that steering group was too large, and decisionmaking was difficult. Decision-making was aggravated furthers because there was no prepared drafts on basis of decision making. As the objectives and benefits to be attained were expressed loosely there was no clear common objective for all the organizations to pursue. In order to overcome the obscurity of the pilot, it would have needed hierarchy. Organization of health care in general is still very hierarchical and some of the actors were expecting firmer steering for the pilot.

\section{Summary}

This paper introduced briefly a process model of partnership evolution in new IT initiatives. The model is still in its infancy and needs still further research. However, some preliminary thoughts can be presented based on these two cases. The cases shared some similarities and some differences in e.g. the magnitude and organization 
of the projects. Both cases shared similar network-like organization, but the outcomes of the projects varied significantly. First case was a success and second one a relative failure.

Based on this study It seems evident, that clan based mechanism is important for successful network. Market and hierarchy are essential, but in they are not adequate in initial stage of network. The role of contract is to create trust and symbolic value for network. The presented framework in Figure explained outcome in two cases. Despite that the reliability and validity of the framework need still more study. It still indicates that IOR has three coordination mechanisms with three dimensions that should be taken into consideration.

\section{References}

1. Markus, M. and D. Robey, Information Technology and Organizational Change: Causal Structure in Theory and Research. Management Science, 1988. 34(5): p. 583-598.

2. Ring, P.S. and A.H. Van de Ven, Developmental Processes of Cooperative Interorganizational Relationship. Academy of Management, 1994. 19(1): p. 90-118.

3. Finnegan, P., R.D. Galliers, and P. Powell. Guidelines for Effective Information Systems Planning in Inter-organisational Environments. in Proceedings of the Seventh European Conference on Information Systems. 1999. Copenhagen: Copenhagen Business School.

4. Salmela, H. and T. Spil. Strategic Information Systems Planning in InterOrganizational Networks: Adapting SISP Approaches to Nerwork Context. in 2nd European Conference on IS Management, Leadership and Governance. 2006. Paris.

5. Williamson, O.E., The Economic Institutions of Capitalism. Firms, Markets, Relational Constructing. 1985: The Free Press.

6. Thorelli, H.B., Networks: Between Markets and Hierarchies. Strategic Management Journal, 1986. 7(1): p. 37-52.

7. Ouchi, W.G., A Conceptual Framework for the Design of Organizational Control Mechanism. Management Science, 1979. 25(9): p. 833- 847.

8. Wilkinson, I., A History of Network and Channels Thinking in Marketing in the 20th Century. Australasian Marketing Journal, 2001. 9(2): p. 23-52.

9. Leblebic, $\mathrm{H}$., et al., Institutional Change and the Transformation of Interorganizational Fields: An Organizational History of the U.S. Radio Broadcasting Industry. Administrative Science Quarterly, 1991. 36(3): p. 333-363.

10. Malone, T.W., J. Yates, and R.I. Benjamin, Electronic Markets and Electronic Hierarchies: Effects of Information Technology on Market Structure and Corporate Strategies. Communications of the ACM, 1987. 30(6): p. 484-497.

11. Choudhury, V., Strategic choices in the development of interorganizational information systems. Information Systems Research, 1997. 8(1): p. 1-24. 
12. Johnston, H.R. and M.R. Vitale, Creating competitive advantage with interorganizational information systems. MIS Quarterly, 1998. 12(2): p. 153165.

13. Van de Ven, A.H., On the Nature, Formation, and Maintenance of Relations Among Organizations. Academy of Management Review, 1976. 1(4): p. 24-36.

14. Williams, T., Interorganisational Information Systems: issues affecting interorganizational cooperation. ELSEVIER, Journal of Strategic Information Systems, 1997. 6(3): p. 231-250.

15. Wilson, D.T., An Integrated Model of Buyer-Seller Relationships. Journal of the Academy of Marketing Science, 1995. 23(4): p. 335-345.

16. Williamson, O.E., Markets and Hierarchies: Analysis and Antitrust Implications. 1975, New York: Free Press.

17. Ouchi, W.G., Markets, Bureaucracies, and Clans. Administrative Science Quarterly, 1980. 25(1).

18. Rodriguez, C., et al., Governance, Power, and Mandated Collaboration in an Interorganizational Network. Administration \& Society, 2007. 39(2): p. 150193.

19. Jarillo, J.C., On Strategic Networks. Strategic Management Journal, 1988. 9(1): p. 31-41.

20. Rapoport, R.N., Three Dilemmas of Action Research. Human Relations, 1970. 23: p. 499-513.

21. Baskerville, R.L. and T. Wood-Harper, Diversity in information systems action research methods. European Journal of Information Systems, 1998. 7(2): p. 90107.

22. Susman, G.I. and R.D. Evered, An Assesment of the Scientific Merits of Action Research. Administrative Science Quarterly, 1978. 23(4): p. 582-603.

23. Checkland, P., From Framework through Experience to Learning: The Essential Nature of Action Research. Discussant's comments, in Information Systems Research: Contemporary Approaches \& Emergent Traditions, H.-E. Nissen, H.K. Klein, and R. Hirscheim, Editors. 1991, Elsevier: Amsterdam.

24. Jönssön, S., Action Research, in Information Systems Research: Contemporary Approaches \& Emergent Traditions, H.-E. Nissen, H.K. Klein, and R. Hirscheim, Editors. 1991, Elsevier: Amsterdam.

25. Argyris, C., Reasoning, Learning and Action: Individual and Organiational. 1982, San Francisco: Jossey-Bass Publishers. 